\title{
Retinal vasculitis associated with Crohn's disease
}

\author{
Miguel Garcia-Diaz, María Mira, Leticia Nevado, Antonio Galván, Alicia Berenguer, \\ Juan Carlos Bureo
}

\begin{abstract}
Summary
Although systemic vasculitis can be a complication of inflammatory bowel disease at several locations (skin, eyes, brain, mesentery, and lung) the association of retinal vasculitis with Crohn's disease is rare. We studied a 26-year-old woman with biopsy-demonstrated Crohn's disease who developed a severe bilateral retinal arteritis and phlebitis, with acute loss of vision.
\end{abstract}

Keywords: retinal vasculitis, Crohn's disease, inflammatory bowel disease

\section{Introduction}

Ocular disorders arising in association with Crohn's disease occur in between 4 and $6 \%$ of cases (see box). ${ }^{1-4}$ Retinal vasculitis, however, is an uncommon complication..$^{5-7}$ There has often been an association found between some of the systemic complications of Crohn's disease. ${ }^{1}$

The pathogenic mechanism of retinal injury could be either vasculitis of vessels ${ }^{5-7}$ or thrombotic occlusion of vessels. ${ }^{1,4,8}$ Fluorescein angiography study is useful in diagnosis of retinal vasculitis. ${ }^{5-7}$

\section{Case report}

A 26-year-old woman with a seven-year history of Crohn's disease was admitted to the hospital after five months of lower left quadrant abdominal pain associated with diarrhoea with blood, vomiting, fever, and weight loss. Her temperature at admission was $37.2^{\circ} \mathrm{C}$.

Initial investigations are shown in the box. A barium enema showed edema, ulceration, mucosal thickening and fistulas penetrating to the vagina. Flexible colonoscopy demonstrated a segmental colitis with rectal and sigmoid involvement. The patient had biopsy-proven Crohn's disease. Treatment (6-methylprednisolone, $1 \mathrm{mg} / \mathrm{kg} /$ day, and parenteral nutrition) resulted in clinical and analytical improvement.

Despite the clinical and analytical improvement, the patient began to suffer an acute loss of vision. On examination, the visual acuity was found to be: right eye 0.1 , left eye 0.6 . The intraocular pressures were: right eye $13 \mathrm{mmHg}$, left eye $14 \mathrm{mmHg}$. Fundoscopy revealed scattered cotton-wool spots in both eyes (figure 1). One cotton-wool spot was on the right eye

\begin{tabular}{|l|}
\hline Ocular manifestations of Crohn's \\
disease \\
\hline - $4-6 \%$ cases \\
- uveitis \\
- corneal ulcers, keratitis \\
- epharitis \\
- myositis \\
- thrombotic retinal artery occlusion \\
\hline
\end{tabular}

\begin{tabular}{|l|}
\hline Biochemical investigations \\
\hline - WBC $14.9 \times 10^{9} / 1$ \\
- neutrophil leucocytosis \\
- haemoglobin $99 \mathrm{~g} / 1$ \\
- haematocrit 0.3 \\
- MCV $72.7 \mathrm{fl}$ \\
- platelets $796 \times 10^{\circ} \times 10^{9} / 1$ \\
- ESR $109 \mathrm{~mm} / \mathrm{h}$ \\
- liver functions normal \\
- kidney functions normal \\
- total serum protein $84 \mathrm{~g} / 1$ \\
- ACE $54 \mathrm{U} / 1$ (normal $10-50$ ) \\
- coagulation studies normal \\
- chest X-ray normal \\
- hepatitis A, B, C, toxoplasma, herpes, \\
cytomegalovirus negative \\
- mantoux negative \\
- NMR imaging of brain normal \\
\hline
\end{tabular}

macula. The retinal veins were tortuous and showed sheathing. The retina was edematous throughout the posterior pole and intraretinal blood was observed near some vessels. We observed uveitis and vitritis and later, preretinal blood.

Intravenous fluorescein angiography showed prolongation of the arm-retinal transit time with swollen optic disks which demonstrated diffuse leakage of fluorescein. It also showed neovascularisation filling and intraretinal haemorrhage on the posterior pole (figure 2).

Cyclophosphamide $(100 \mathrm{mg} /$ day $)$ and prednisone $(50 \mathrm{mg} /$ day) was employed but only improvement of the uveitis and vitritis was observed. The retinal vasculitis did not improve.

Six weeks later, she could only count fingers at most $3 \mathrm{~m}$ with the right eye. The visual acuity of the left eye remained unchanged. 

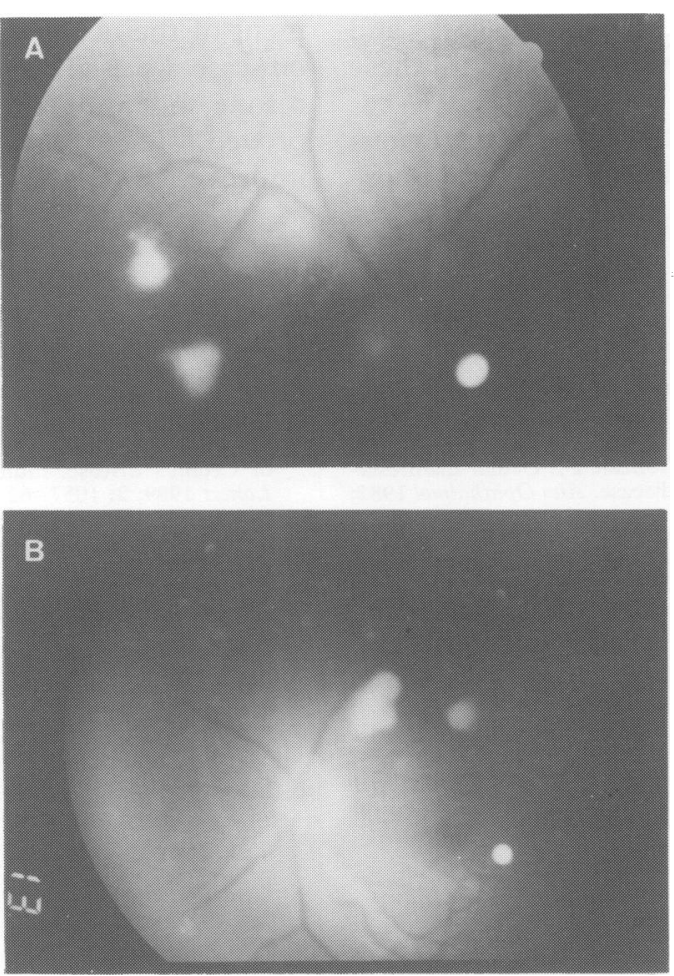

Figure 1 Posterior poles of both eyes: cotton-wool spots are present. A: right eye. B: left eye

\section{Discussion}

A diagnosis of retinal vasculitis is made on the basis of sheathing of the walls of retinal vessels, haemorrhages in the retina, and late staining of the walls of affected vessels. Retinal vasculitis has been associated with cotton-wool spots due to retinal ischaemia. ${ }^{5-7}$

In Crohn's disease and in ulcerative colitis, the vasculitis could affect several tissues (retina, ${ }^{5-7}$ skin, $^{9}$ brain, ${ }^{10}$ bowel,,${ }^{11,13}$ lung $^{12}$ ). A possible pathogenic mechanism in Crohn's disease could be inflammatory microvascular occlusion, associated with vasculitis. In the affected bowel, the injury is focal and it may occur in the absence of either macroscopic or microscopic disease. ${ }^{13}$ The pathogenic sequence of events in Crohn's disease might be: vascular injury, focal arteritis, fibrin deposition and arterial occlusion followed by tissue infarction or neovascularisation. ${ }^{11,13}$ Granulomatous vasculitis was suggested to be the mechanism of tissue injury ${ }^{13}$ : granulomatous inflammation was associated with focal disruption of the blood vessel walls, adherence of chronic inflammatory cells to the luminal surface of the lesion, and fibrin deposition. This pathogenic sequence was only seen in specimens from small and large bowel Crohn's disease. ${ }^{13}$ However, this granulomatous inflammation has not been observed in other tissues, although immunochemical staining techniques were not used to identify vascular structures and granulomas in these studies..$^{9-12}$

Retinal vasculitis is uncommon in Crohn's disease, although there are some systemic diseases (sarcoidosis, tuberculosis, syphilis, toxoplasmosis, cytomegalovirus, herpes zoster, temporal arteritis, polyarteritis nodosum,
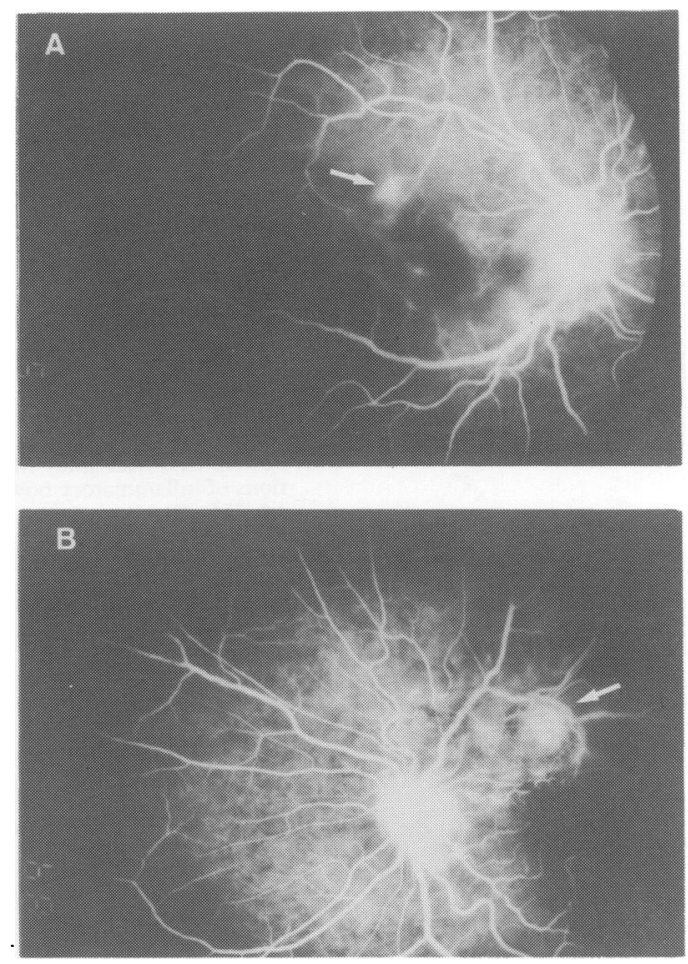

Figure 2 Intravenous fluorescein angiogram of both eyes after injection of fluorescein, showing prominent leakage of the dye from the optic disk and the new vessels growing at the posterior pole. The arrows show leakage of fluorescein from the neovascularization. A: right eye. B: left eye

systemic lupus erythematosus and multiple sclerosis) which can be associated with retinal vasculitis, and there is also an idiopathic presentation (Eale's disease). ${ }^{14}$ These other systemic diseases were rejected on the basis of negative results in their differential diagnosis.

Retinal arterial occlusions have been described in previous reports of patients with Crohn's disease, but the authors saw no evidence of intrinsic retinal vascular disease in the fluorescein angiography and the aetiology of these lesions was thrombi occluding small vessels. ${ }^{1,4}$ In our patient, the absence of any previous systemic manifestation of thromboembolic phenomena, and the normal coagulation studies and platelet count when the acute loss of vision began did not suggest a thromboembolic phenomenon. Moreover, the fluorescein angiography of our patient demonstrated retinal vasculitis.

In our patient, the inflammatory bowel disease complication manifested as acute loss of vision due to severe, bilateral, obliterative and proliferative retinal vasculitis in which the arteries were predominantly affected. We observed cotton-wool spots in her eyes suggesting tissue ischaemia, leakage of fluorescein indicating haemorrhage, and neovascularisation (figures 1 and 2).

There are other previously reported cases that share some similarities with our case. ${ }^{5-7}$ Two involved patients with Crohn's disease who have optic nerve vasculitis with secondary involvement of retinal vessels, ${ }^{6-7}$ and another was of a patient with arterial and venous 
vasculitis. ${ }^{5}$ Papillitis, haemorrhages and sheathing of vessels was observed in these patients. ${ }^{5-7}$

The treatments employed in these previous reports have been prednisone or cyclophosphamide plus corticosteroids. The improve-

1 Hopkins DJ, Horan E, Burton IL, Clamp SE, De Domball FT, Goligher JC. Ocular disorders in a series of 332 patients with Crohn's disease. Br $\mathcal{f}$ Ophthalmol 1974; 58: 732-7.

2 Greenstein AJ, Janowitz HD, Sachar DB. The extraintestinal complications of Crohn's disease and ulcerative colitis: a study of 700 patients. Medicine 1976; 55: 401-11.

3 Petrelli EA, McKinley M, Troncale FJ. Ocular manifestations of inflammatory bowel disease. Ann Ophthalmol 1982; 14: $356-60$

4 Schneiderman JH, Sharpe JA, Sutton DMC. Cerebral and retinal vascular complications of inflammatory bowel disease. Ann Neurol 1979; 5: 331-7.

5 Duker JS, Brown GC, Brooks I. Retinal vasculitis in

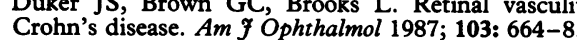

6 Sedwick LA, Klingele TC, Burde RM, Behrens MM. Optic neuritis in inflammatory bowel disease. $\mathcal{F}$ Clin Neuro Oph-

Macoul KI. Ocular changes in granulomatus ileocolitis. Arch Ophthalmol 1970; 84: 95-7.

8 Novotny DA, Rubin RJ, Slezak FA, Porter JA. Arterial thromboembolic complications of inflammatory bowel disease. Dis Colon Rectum 1992; 35: 193-6. ment of the ocular damage was limited..$^{5-7}$ In our case, we used cyclophosphamide plus prednisone, but only the uveitis and vitritis improved. The retinal vessel lesions did not improve.

9 Wackers FJ, Tytgat GN, Vreeken J. Necrotizing vasculiti and ulcerative colitis. $B M \mathcal{F}$ 1974; 4: 83-4.

10 Nelson JN, Barron MM, Riggs JE, Gutmann L, Schochet SS. Cerebral vasculitis and ulcerative colitis. Neurology 1986; 36: 719-21.

11 Wakefield AJ, Dhillon AP, Rowles PM, et al. Pathogenesis of Crohn's disease: multifocal gastrointestinal infarction. Lancet 1989; 2: 1057-62.

12 Collins WJ, Bendig DW, Taylor WF. Pulmonary vasculiti complicating childhood ulcerative colitis. Gastroenterology 1979; 77: 1091-3.

13 Wakefield AJ, Sankey EA, Dhillon AP, et al. Granulomatous vasculitis in Crohn's disease. Gastroenterology 1991; 100 $1279-87$

14 Jampol LM, Isenberg SJ, Goldberg MF. Occlusive retina arteriolitis with neovascularization. Am f Ophthalmol 1976; 81: 583-9.

\title{
Occult small bowel adenocarcinoma complicating Crohn's disease: a report of three cases
}

\author{
CD Gillen, CA Wilson, RS Walmsley, DSA Sanders, ST O'Dwyer, RN Allan
}

\begin{abstract}
Summary
Three patients with Crohn's disease are described who were treated by ileal resection for intestinal obstruction. Histological examination of the resected specimen in each case established the diagnosis of adenocarcinoma of the small intestine complicating Crohn's disease. This diagnosis should be considered in patients with longstanding macroscopic Crohn's disease who present with severe or recurrent symptoms. The diagnosis may not be apparent on routine radiological examination or even macroscopically at laparotomy.
\end{abstract}

Keywords: Crohn's disease, small bowel, adenocarcinoma

Queen Elizabeth

Hospital, Edgbaston, Birmingham, UK

CD Gillen

RS Walmsley

ST O'Dwyer

RN Allan

Department of

Histopathology

CA Wilson

DSA Sanders

Correspondence to

Dr CD Gillen,

Queen Elizabeth Hospital,

Edgbaston, Birmingham

B15 2TH, UK

Accepted 4 October 1994 the management of patients with longstanding macroscopic small bowel Crohn's disease. ${ }^{4}$ In this paper we describe three examples of adenocarcinoma of the ileum complicating Crohn's disease which were only apparent on histological examination of the resected specimens.

\section{Case reports}

\section{Case 1}

A diagnosis of ileal Crohn's disease in this white man, born in June 1949, was established on radiological examination in 1969 . He had further abdominal symptoms in 1975 when radiological studies confirmed the changes of terminal ileal Crohn's disease with a localised ileocaecal fistula. He re-presented in July 1992 with a three month history of right-sided colicky abdominal pain, nausea, intermittent constipation and $10 \mathrm{~kg}$ weight loss. Further radiological assessment confirmed an irregular $8 \mathrm{~cm}$ of terminal ileum with abnormal mucosa and several areas of narrowing with mucosal irregularity adjacent to the ileo-caecal valve. At laparotomy the appearance macroscopically was described as typical of Crohn's disease and he was treated by distal ileal resection. The resected specimen comprised an $11 \mathrm{~cm}$ length of small bowel with a $4 \mathrm{~cm}$ diameter ulcerated area with some transmural thickening. There were three distinct areas of mucosal irregularity. Macroscopically, the changes were considered typical of Crohn's disease. However histological examination revealed a moderately well differentiated adenocarcinoma, extending 